\title{
Double blind randomised controlled trial of topical glyceryl trinitrate in anal fissure
} S E Kenny, T Irvine, C P Driver, A T Nunn, P D Losty, M O Jones, R R Turnock,
G L Lamont, D A Lloyd
Department of Paediatric Surgery, Institute of Child

Health, Alder Hey Children's Hospital, Eaton Rd, Liverpool

L12 2AP, UK

T Irvine

C P Driver

M O Jones

R R Turnock

G L Lamont

Department of Pharmacology,

Institute of Child

Health, Alder Hey

Children's Hospital

A T Nunn

University of Liverpool, Liverpool, UK

S E Kenny

P D Losty

D A Lloyd

Correspondence to: Mr S E Kenny, Department of Paediatric Surgery, Institute of Child Health, Alder Hey Children's Hospital, Eaton Rd, Liverpool L12 2AP, UK simon.kenny@liv.ac.uk

Accepted 12 April 2001

\begin{abstract}
Aims-To determine the effectiveness and safety of topical glyceryl trinitrate (GTN) in the management of acute anal fissure in children.

Methods-Individual children were randomised to receive GTN paste or placebo for six weeks in addition to oral senna and lactulose. Patients took laxatives alone for a further 10 weeks. Each week a research nurse telephoned families to assess pain scores and give advice. Main outcome measures were validated standardised pain scores and time to painless defaecation.

Results-Forty subjects were recruited from 46 eligible children; 31 children completed the trial (13 in the GTN group and 18 in the placebo group). No differences in the proportion of those achieving pain free defaecation with relation to time were seen between the two groups. Similarly, there were no significant differences in pain scores between the two groups over the 16 week study period. However, in both groups pain scores had decreased significantly. There were no differences in the incidence of rectal bleeding, faecal soiling, presence of visible fissure, skin tag, or faecal loading at outpatient review at the time of recruitment, or at 6 weeks and 16 weeks. No serious adverse effects were observed.

Conclusions-This study suggests that $0.2 \%$ GTN paste is ineffective in the treatment of acute anal fissures in childhood. However the overall fissure healing rate is high $(84 \%)$ with associated reduction in pain scores, suggesting that a nurse based treatment programme can achieve a high rate of fissure healing.
\end{abstract}

(Arch Dis Child 2001;85:404-407)

Keywords: anal fissure; glyceryl trinitrate; randomised controlled trial

Acute anal fissure in children, characterised by pain on defaecation and rectal bleeding, is a common ailment. Fissures are often precipitated by an episode of constipation, with passage of a hard stool resulting in a perianal tear. Current treatment is based on limited data mainly extrapolated from adult experience, with few therapies in children subjected to controlled or randomised trials.

Recent work in adults has suggested that anal sphincter spasm and subsequent ischaemia may be important factors in the development and persistence of an acute fissure. ${ }^{1}$ Evidence to support this includes the observation that reducing anal sphincter pressure, surgically or pharmacologically, results in healing of both acute and chronic fissures. ${ }^{2-4}$ Moreover, animal and human studies have shown that nitric oxide (NO) acts as an inhibitory neurotransmitter in both the internal and external sphincter, and thus may have an important role in the pathophysiology of fissures. ${ }^{5}$

Current options available for the management of acute anal fissures in children include simple laxative therapy, fissurectomy, ${ }^{6}$ anal dilatation under general anaesthesia, ${ }^{7}$ or lateral internal sphincterotomy, ${ }^{7}$ none of which have been subjected to a controlled clinical trial. Concerns about surgical management centre on the potential for an uncontrolled anal sphincter injury that may result in a degree of faecal incontinence. ${ }^{8}$

Glyceryl trinitrate (GTN) has clearly been shown to be of benefit to adults with anal fissures. ${ }^{9}$ In children, a randomised controlled trial (RCT) comparing GTN, topical anaesthetic agents, and placebo showed that GTN was superior, with relief of symptoms in over $90 \%$ of GTN treated patients, ${ }^{10}$ although the use of laxative therapy was not controlled. The objective of the current study was to test further the efficacy and safety of topical GTN as an adjunct to laxative treatment in the management of childhood anal fissure.

\section{Materials and methods}

Ethical approval for the study was obtained from the local research and ethics committee.

\section{HYPOTHESIS}

The study was a randomised controlled trial to test the hypothesis that topical GTN is an effective and safe method of promoting healing of childhood anal fissure.

PROTOCOL

Study population

All children presenting with anal fissure were considered for inclusion in the trial. A positive diagnosis of anal fissure was made in the presence of: (1) a visible anal fissure; and (2) painful defaecation with or without rectal bleeding on defaecation. Patients were excluded if there was a history of recurrent fissure, congenital heart disease, or severe headaches.

\section{Medication}

Children were assigned to receive twice daily perianal $0.2 \%$ GTN or placebo paste for six weeks. Parents were instructed to apply the trial ointment by measuring out the appropriate amount on a ruler $(0.1 \mathrm{~g}=1 \mathrm{~cm})$ and then 
Table 1 Dosage protocol for $0.2 \%$ GTN paste and oral laxative treatment

\begin{tabular}{llll}
\hline Age $(y)$ & Dose $0.2 \%$ GTN & Lactulose & Senna \\
\hline$<1$ & 0.2 g twice daily & $5 \mathrm{ml}$ twice daily & 0 \\
$1-5$ & 0.3 g twice daily & $5 \mathrm{ml}$ twice daily & $2.5 \mathrm{ml}$ once daily \\
$5-10$ & 0.4 g twice daily & $5 \mathrm{ml}$ twice daily & $5 \mathrm{ml}$ once daily \\
$10-15$ & 0.5 g twice daily & $10 \mathrm{ml}$ twice daily & $5 \mathrm{ml}$ twice daily \\
\hline
\end{tabular}

Table 2 Demographic variables and clinical presenting characteristics

\begin{tabular}{lllll}
\hline & $\begin{array}{l}\text { Age }(y) \\
\text { (mean, range) }\end{array}$ & $\begin{array}{l}\text { Sex } \\
(M / F)\end{array}$ & $\begin{array}{l}\text { Duration of symptoms } \\
\text { (wh) } \\
\text { (mean, range })\end{array}$ & $\begin{array}{l}\text { Previous treatment } \\
(\%)\end{array}$ \\
\hline GTN & $2.49(0.7-6.2)$ & $11 / 9$ & $32.9(6-104)$ & $14(70 \%)$ \\
Placebo & $5.05(0.1-15.2)$ & $7 / 13$ & $29.4(6-150)$ & $16(80 \%)$ \\
Combined & $3.83(0.1-15.9)$ & $18 / 22$ & $31.0(6-150)$ & $30(75 \%)$ \\
\hline
\end{tabular}

applying this to the perianal region. Parents were advised not to apply trial ointment directly into the anal canal. All children received senna and lactulose for 16 weeks. Doses of all medications were age related (see table 1) and could be adjusted depending on response. All medication was dispensed directly from the hospital pharmacy with written instructions.

\section{ASSIGNMENT}

Subjects were individually randomised by computer (Statmate, Graphpad Software Inc., California, USA). The randomisation schedule was held by the hospital pharmacy that dispensed all medications. The involved clinicians were blinded to the allocation schedule until the final child had completed the trial.

MASKING

Trial ointments were prepared in identical white tubes by staff not involved in the trial. GTN and placebo ointments looked, felt, and smelt identical.

\section{MONITORING}

Patients were contacted weekly by telephone by the research nurse (TI), who ensured that the paste was being correctly applied, identified any adverse drug reactions, adjusted the laxative dose if necessary, and performed a pain assessment. Pain was assessed weekly by parental or patient completion of a previously

Table 3 Children who did not complete the trial

\begin{tabular}{|c|c|c|c|c|c|}
\hline Group & Age (y) & Sex & $\begin{array}{l}\text { When withdrew } \\
(w k)\end{array}$ & $\begin{array}{l}\text { Pain score on } \\
\text { withdrawal }\end{array}$ & Reason \\
\hline GTN & 2.4 & $\mathrm{~F}$ & 7 & 0 & Lost contact \\
\hline GTN & 2.7 & $\mathrm{~F}$ & 11 & 8 & $\begin{array}{l}\text { Persistent high pain scores; no } \\
\text { fissure when examined under } \\
\text { anaesthetic }\end{array}$ \\
\hline GTN & 1.3 & $\mathrm{~F}$ & 5 & 8 & $\begin{array}{l}\text { Persistent high pain scores; } \\
\text { coryzal symptoms thought by } \\
\text { parents to be due to GTN }\end{array}$ \\
\hline GTN & 0.7 & M & 1 & 10 & No reason given \\
\hline GTN & 1.2 & $\mathrm{~F}$ & 4 & 8 & $\begin{array}{l}\text { Perineal rash; examination } \\
\text { under anaesthetic at week } 4 \text { : } \\
\text { fissure healed, pain free at } 8 \\
\text { weeks and off laxatives }\end{array}$ \\
\hline GTN & 1.2 & M & 1 & 8 & $\begin{array}{l}\text { Gastrointestinal upset (colicky } \\
\text { pains and vomiting) }\end{array}$ \\
\hline GTN & 3.6 & $\mathrm{~F}$ & 14 & 2 & $\begin{array}{l}\text { Parental dissatisfaction with } \\
\text { improvement; underwent } \\
\text { fissurectomy }\end{array}$ \\
\hline Placebo & 1.8 & $\mathrm{~F}$ & 8 & 9 & $\begin{array}{l}\text { Persistent high pain scores; } \\
\text { underwent fissurectomy }\end{array}$ \\
\hline Placebo & 2.6 & M & 8 & 7 & $\begin{array}{l}\text { Persistent high pain scores; } \\
\text { underwent fissurectomy }\end{array}$ \\
\hline
\end{tabular}

validated linear analogue pain score. ${ }^{11}{ }^{12}$ In children under 5 years of age, pain assessment was by parental assessment of a visual analogue pain score. In children over 5 years of age a visual analogue pain score or a Smiley analogue pain score was used, depending on the child's maturity. ${ }^{13}$ At 6 and 16 weeks, children were reviewed in the hospital outpatient clinic. Investigators unaware of group allocation completed a structured assessment of symptoms and signs of anal fissure (see secondary outcome measures below).

PRIMARY OUTCOME MEASURES

The main outcome measure in this study was time to painless defaecation in weeks.

\section{Secondary outcome measures}

Pain scores, and assessment for evidence of anal fissure (rectal bleeding, visible fissure, skin tag) and presence of constipation (faecal soiling, faecal loading) at beginning of study, after completing six weeks application of paste and at 16 weeks from commencing treatment. Constipation was defined as infrequent passage of bulky firm stool that was difficult for the child. ${ }^{14}$

\section{STATISTICAL ANALYSIS}

Demographic and clinical presentation data were compared by Mann-Whitney U test or Fisher's exact test as appropriate. Time to painless defaecation in weeks was compared using the log rank test on Kaplan-Meier survival curves. Paired weekly pain scores were compared using multiple paired $t$ tests with Levene's test for equality of variances. Data on symptoms and signs obtained at outpatient review were compared by Fisher's exact test. A $\mathrm{p}$ value less than 0.05 was considered significant.

\section{Results}

DEMOGRAPHICS AND CLINICAL PRESENTATION CHARACTERISTICS

Table 2 shows demographic data. There were no differences in mean age $(\mathrm{p}=0.14)$, male:female ratio $(p=0.35)$, or duration of symptoms between GTN and placebo groups $(\mathrm{p}=0.55)$. A similar proportion of children had received medical treatment prior to recruitment $(p=0.71)$. There were no differences in the incidence of constipation ( $p=1.33)$, bleeding $(p=0.69)$, presence of anal skin tags $(\mathrm{p}=1.00)$, or faecal loading $(\mathrm{p}=1.00)$ between the two groups.

PARTICIPANT FLOW

Forty subjects were recruited from 46 eligible children. Figure 1 summarises the course of the trial. Thirty one children completed the trial, 13 in the GTN group and 18 in the placebo group. Seven children in the GTN group and two children in the placebo group did not complete the trial (see table 3).

\section{ADVERSE EFFECTS}

Putative side effects reported by parents were coryzal symptoms $(n=1)$, an erythematous perineal rash $(n=1)$, and colicky abdominal 


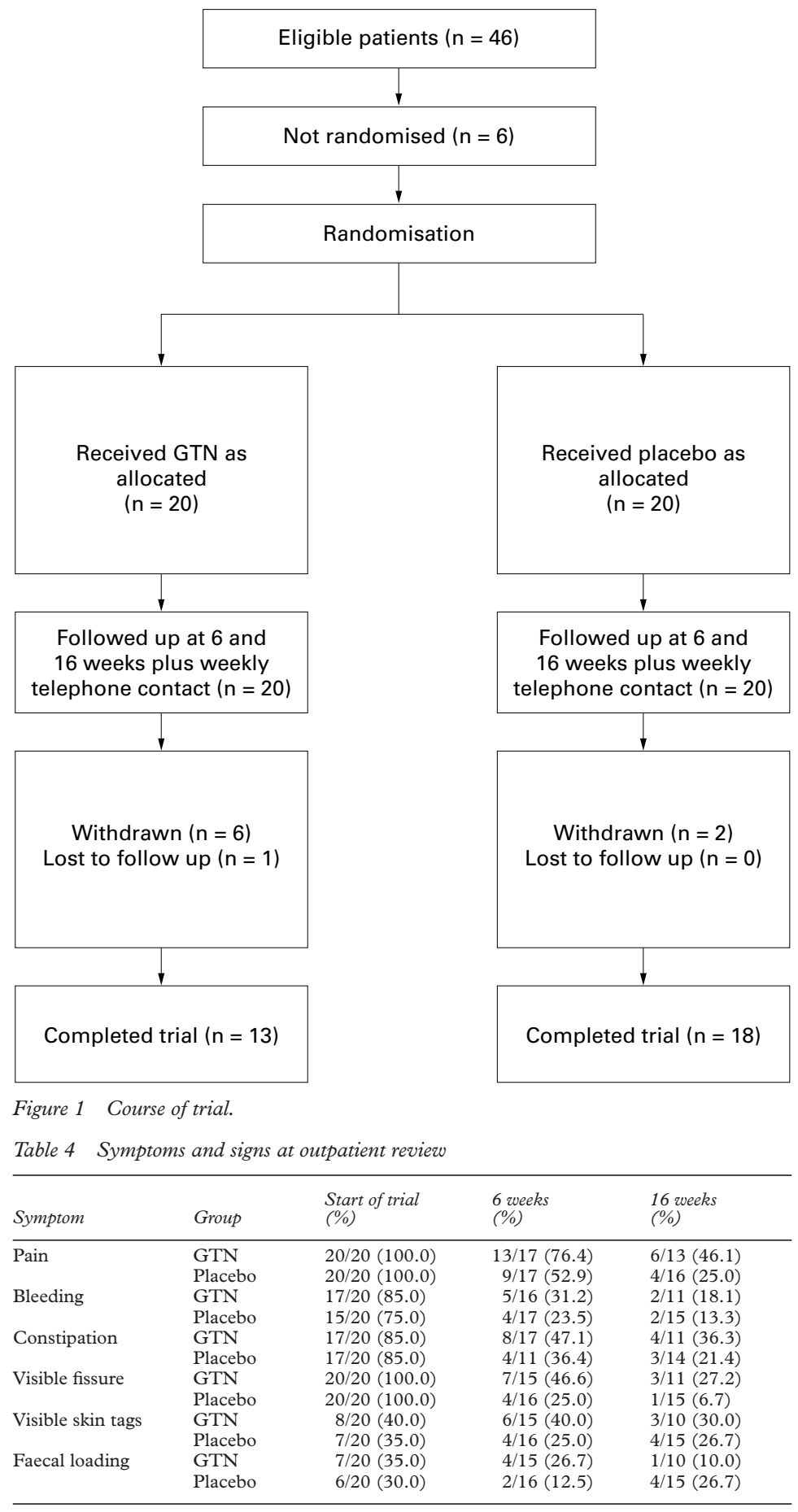

pain and vomiting (which simultaneously affected other family members, $n=1$ ). The perineal rash resolved on discontinuing the topical paste, later revealed to be GTN. No headaches were reported. There was no difference in the proportion of children completing the trial between groups $(p=0.15)$.

\section{ANALYSIS}

There was no difference in the time to achieving pain free defaecation between the two study groups ( $p=0.22$, log rank test; fig 2). Similarly, there were no significant differences in standardised pain scores in the two groups over the 16 week study period ( $\mathrm{p}=0.68, t$ test; fig

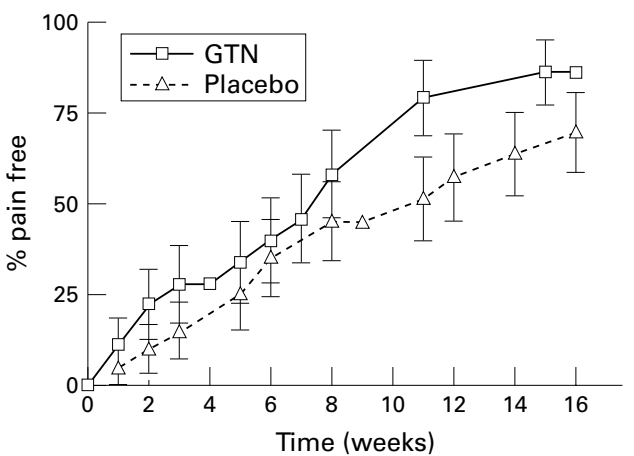

Figure 2 Kaplan-Meier survival curve showing percentage of trial participants achieving painless defaecation over time. Bars $=$ SEM.

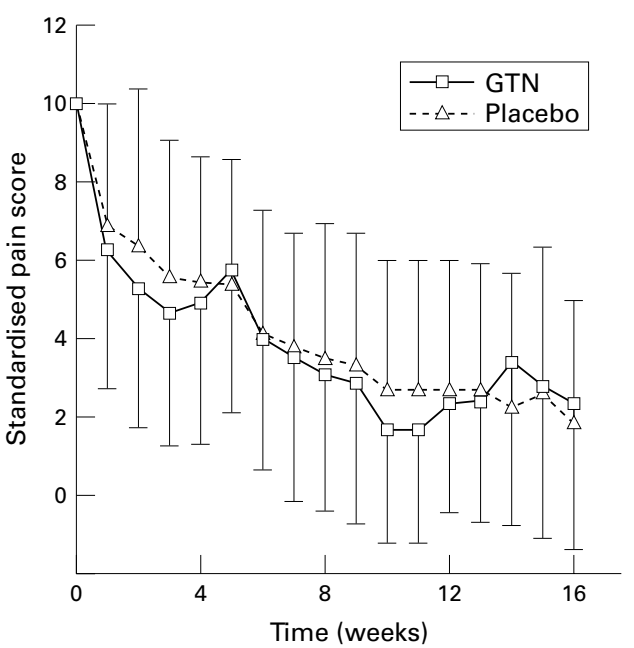

Figure 3 Standardised pain scores in GTN and placebo groups over the course of the trial. Bars $=S D$.

3). However, in both groups pain scores had decreased significantly $(\mathrm{p}<0.001$, paired $t$ test). There were no differences in the incidence of rectal bleeding, presence of visible fissure, skin tag, faecal soiling, or faecal loading at outpatient review at 0,6 , and 16 weeks (table 4 ). Overall, the fissure had healed in $22 / 26$ children at 16 week review ( $84.6 \%$, table 4$)$.

\section{Discussion}

In this study no differences were found in rates of fissure healing between the group receiving GTN and those receiving placebo. This finding differs from that reported in adult studies ${ }^{9}$ and is notably different from the data reported by Tander et al in a paediatric cohort. ${ }^{10}$ Given the relatively small number of children who completed the trial, this study is powered to find a difference in pain scores of 4.98 at the $90 \%$ level. Therefore, although this study is unlikely to have picked up small effects of GTN it is likely to have identified differences similar in magnitude to those reported in adults and children. ${ }^{9}{ }^{10}$ Administration of GTN paste was not associated with significant side effects.

There are a number of possible explanations for the different findings of this study. The pathogenesis and/or natural history of anal fissure in children may be different in children than in adults. Previous adult based series have 
suggested that ischaemia of the sphincter mechanism is an important mechanism in the pathogenesis of adult fissures. ${ }^{1}$ A pharmacological agent, such as GTN, that reduces anal sphincter spasm and increases perianal blood flow would appear a logical therapeutic intervention. It would however seem reasonable to hypothesise that children are more likely than adults to adopt maladaptive patterns of behaviour in response to painful defaecation, such as faecal retention, that are less amenable to pharmacological intervention. ${ }^{15}$ Interestingly, Tander et al did not control for adjunct laxative therapy between the groups. ${ }^{10}$ As this has been the mainstay of management of childhood constipation and fissures, this may have significantly biased the outcome data.

The weekly telephone contact between research nurse and families may have had a positive effect that masked the effect of GTN alone. The overall fissure healing rate of $84.6 \%$ in children completing the trial is identical to the healing rates of $84 \%$ seen in the GTN treated group reported by Tander and colleagues, ${ }^{10}$ but differs notably from the 35\% healing rate in their placebo treated group. The healing rate is also similar to that achieved in children by fissurectomy. ${ }^{6}$ The weekly telephone contact provided both moral and practical support to parents that supplemented explanations given in oral and written form by the participating surgeons in the outpatient clinic. The nurse practitioner reported frequent confusion and miscomprehension about the laxative treatment among parents, even shortly following medical consultation. Such failure to understand information given during a consultation may be a result of a number of factors, including poor communication skills and the receptive learning skills of the parent. ${ }^{16}$ The role of frequent nurse contact in the effective management of anal fissure in children is a potentially fruitful avenue of enquiry.

A further explanation of these results could be that the formulation or administration of the GTN paste was incorrect or ineffective. It was felt both unethical and impractical to subject the children in the study to invasive anorectal manometry and therefore objective evidence of effective dosage is lacking. However, the ointment was obtained from the major supplier of GTN paste in the UK, and stored and administered according to published advice. ${ }^{9}$ It is therefore unlikely that degradation of the active agent would have occurred.

The findings from this study suggest that $0.2 \%$ GTN paste is not beneficial in the management of acute anal fissures in childhood. However, the study has shown the potential of a nurse based treatment programme to achieve a high rate of fissure healing. Further studies are required to establish the role of simple laxative therapy, nurse based treatment, and surgery in the management of childhood anal fissures in order to develop a rational, evidence based approach to the treatment of this common childhood ailment.

1 Schouten W, Briel J, Auwerda J. Relationship between anal pressure and anodermal blood flow: the vascular pathogenesis of anal fissures. Dis Colon Rectum 1994;34:664-9.

2 Lund JN, Scholefield JH. Glyceryl trinitrate is an effective treatment for anal fissure. Dis Colon Rectum 1997;40:46870 .

3 Kennedy ML, Sowter S, Nguyen H, Lubowski DZ. Glyceryl trinitrate ointment for the treatment of chronic anal fissure: results of a placebo-controlled trial and long-term followup. Dis Colon Rectum 1999;42:1000-6.

4 Carapeti EA, Kamm MA, McDonald PJ, et al. Randomised controlled trial shows that glyceryl trinitrate heals anal fiscontrolled trial shows that glyceryl trinitrate heals anal fis-
sures, higher doses are not more effective, and there is a sures, higher doses are not more effective,
high recurrence rate. Gut 1999;44:727-30.

5 Stebbing J. Nitric oxide synthase neurones and neuromuscular behaviour of the anorectum. Ann $R$ Coll Surg Engl ular behaviour of

1998;80:137-45.
6 Lambe GF, Driver CP, Morton S, Turnock RR. Fissurectomy as a treatment for anal fissures in children. Ann R Coll Surg Engl 2000;82:254-7.

7 Evans DA, Cohen A, Dehn TC, et al. Manual dilatation of the anus vs. lateral subcutaneous sphincterotomy in the treatment of chronic fissure-in-ano. Results of a prospective, randomized, clinical trial. Br f Surg 1996;83:571.

8 Schouten WR, Briel JW, Auwerda JJ, Boerma MO. Anal fissure: new concepts in pathogenesis and treatment. Scand f Gastroenterol Suppl 1996;218:78-81.

9 Lund JN, Scholefield JH. A randomised, prospective, double-blind, placebo-controlled trial of glyceryl trinitrate ointment in treatment of anal fissure. Lancet 1997;349:1114.

10 Tander B, Guven A, Demirbag S, et al. A prospective, randomized, double-blind, placebo-controlled trial of glyceryltrinitrate ointment in the treatment of children with anal fissure. F Pediatr Surg 1999;34:1810-12

11 Jakobs $H$, Rister $M$. Team assessment of pain in children. Klin Padiatr 1997;209:384-8.

12 Wilson GA, Doyle E. Validation of three paediatric pain scores for use by parents. Anaesthesia 1996;51:1005-7.

13 Tyler DC, Tu A, Douthit J, Chapman CR. Toward validation of pain measurement tools for children: a pilot study. Pain 1993;52:301-9.

14 Rowe M, O’Neill J, Grosfeld J, et al. Anorectal disorders. In: Baxter S, ed. Essential pediatric surgery. St Louis: MosbyYear Book Inc., 1995:600.

15 Pugh D. The psychosocial aspects of paediatrics, 2nd edn. Pugh D. The psychosocial aspects of paediatr

16 Kai J. Parents' difficulties and information needs in coping with acute illness in preschool children: a qualitative study. BMF 1996;313:987-90. 